\title{
CHROMIUM(III) - CHROMIUM(VI) INTERCONVERSIONS IN SEAWATER
}

\section{C.H. VAN DER WEIJDEN and M. REITH}

Vening Meinesz Laboratorium, Department of Geochemistry, Institute of Earth Sciences, University of Utrecht, Budapestlaan 4, P.O. Box 80.021, 3508 TA Utrecht (The Netherlands)

(Received December 11, 1981; revision accepted June 2, 1982)

\section{ABSTRACT}

Van der Weijden, C.H. and Reith, M. 1982. Chromium(III)-chromium(VI) interconversions in seawater. Mar. Chem., 11: 565-572.

The stable form of dissolved chromium in oxygenated seawater is $\mathrm{Cr}$ (VI). But $\mathrm{Cr}$ (III)species are also present at an analytically significant level. It is shown that $\mathrm{Cr}$ (III) is oxidized only slowly by dissolved oxygen, and that manganese oxide is a strong catalyst for such oxidation. However, the low oceanic concentration of suspended $\mathrm{MnO}_{2}$ impedes the conclusion that the former process is quantitatively less important than the latter one. The distribution of dissolved chromium among $\mathrm{Cr}$ (VI)- and $\mathrm{Cr}$ (III)-species is probably kinetically controlled.

\section{INTRODUCTION}

Little doubt exists that dissolved chromium in seawater is predominantly present as $\mathrm{Cr}$ (VI)-species. However, $\mathrm{Cr}$ (III)-species always seem to be present at a level of analytical significance. Based on thermodynamic data, no Cr(III) is expected to be present.

Elderfield (1970) suggested five possibilities to explain this discrepancy:

(1) published analytical results do not represent speciation in true solution;

(2) published stability constants are inapplicable;

(3) relevant species have been overlooked;

(4) there is no equilibrium with the atmosphere;

(5) kinetics of redox reactions $\mathrm{Cr}$ (III) $-\mathrm{Cr}$ (VI) are sluggish.

Indeed, many of the earlier published analytical results on chromium speciation can be discarded. In this paper we will address ourselves to the other possibilities mentioned above.

\section{STABILITY OF Cr (III)- AND Cr (VI)-SPECIES IN SEAWATER}

No important changes of stability constants of chromium complexes have been reported since Elderfield's paper. In comparison with hydrolysis and oxidation of $\mathrm{Cr}$ (III), complexes with chloride, fluoride, sulphate and carbon- 
ate ions only play a minor role. The stability field of $\mathrm{Cr}$ (III), in terms of $\mathrm{p} \epsilon$ and $\mathrm{pH}$, cannot be expanded by complexing with those inorganic ligands. Because of the low concentration of dissolved organic matter in seawater, the role of organic complexes of $\mathrm{Cr}$ (III) is also small.

The contribution of hydrolysis products to the $\mathrm{Cr}$ (III) concentration is shown in Fig. 1, based on data given in Table I. The tendency of $\mathrm{Cr}$ (III) to become adsorbed on mineral surfaces in the sea can be explained by the predominance of the dihydroxy complex (cf. James and Healy, 1972). At the low level of chromium concentrations in seawater $(\Sigma \mathrm{Cr} \simeq 4-5 \mathrm{nM})$, the presence of dinuclear and trinuclear chromium(III)-hydroxy complexes can be practically ruled out. The $\mathrm{p} \epsilon-\mathrm{pH}$ stability diagram for chromium in seawater is given in Fig. 2. The boundary between $\mathrm{Cr}$ (III)- and $\mathrm{Cr}$ (VI)species is shifted by $1 / 3$ pe-unit for every ten-fold change in the ratio. This means that for most of the acceptable data on chromium speciation in seawater $p \epsilon \simeq 5-6$. This value is much lower than the apparent $\mathrm{p} \epsilon$ value for

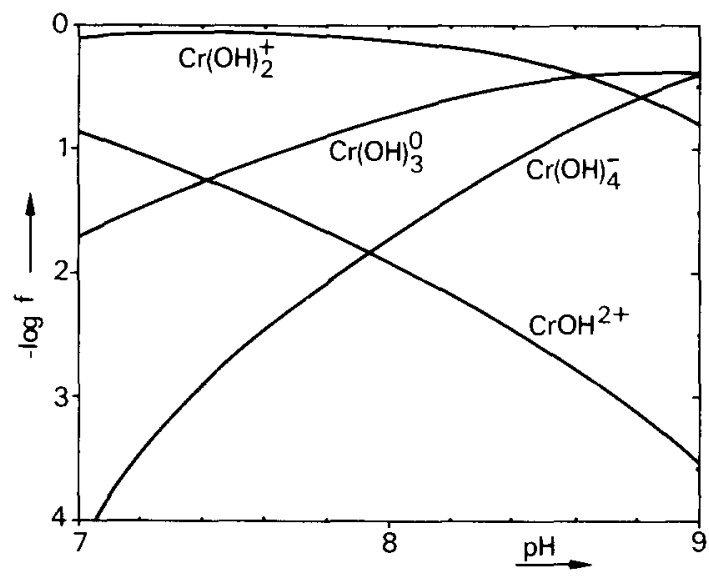

Fig. 1. pH-dependence of $\mathrm{Cr}$ (III) speciation relative to the total $\mathrm{Cr}$ (III) concentration.

\section{TABLE I}

Apparent stability constants $\left(298 \mathrm{~K}, I=0.75, \gamma_{H^{+}}=0.95\right)$ calculated for pertinent reactions relevant for chromium speciation in seawater

\begin{tabular}{lll}
\hline Equation & log $K^{1}$ & Reference \\
\hline (1) $\mathrm{Cr}^{3+}+\mathrm{H}_{2} \mathrm{O} \rightleftharpoons \mathrm{Cr}(\mathrm{OH})^{2+}+\mathrm{H}^{+}$ & -4.4 & Baes and Mesmer (1976) \\
(2) $\mathrm{Cr}^{3+}+2 \mathrm{H}_{2} \mathrm{O} \rightleftharpoons \mathrm{Cr}(\mathrm{OH})_{2}^{+}+2 \mathrm{H}^{+}$ & -10.6 & Baes and Mesmer (1976) \\
(3) $\mathrm{Cr}^{3+}+3 \mathrm{H}_{2} \mathrm{O} \rightleftharpoons \mathrm{Cr}(\mathrm{OH})_{3}+3 \mathrm{H}^{+}$ & -19.2 & Baes and Mesmer (1976) \\
(4) $\mathrm{Cr}^{3+}+4 \mathrm{H}_{2} \mathrm{O} \rightleftharpoons \mathrm{Cr}(\mathrm{OH})_{4}^{-}+4 \mathrm{H}^{+}$ & -28.2 & Baes and Mesmer (1976) \\
(5) $\mathrm{HCrO}_{4}^{-} \mathrm{CrO}_{4}^{2-}+\mathrm{H}^{+}$ & -5.8 & Baes and Mesmer (1976) \\
(6) $\mathrm{Cr}(\mathrm{OH})^{2+}+3 \mathrm{H}_{2} \mathrm{O} \rightleftharpoons \mathrm{CrO}_{4}^{2-}+7 \mathrm{H}^{+}+3 \mathrm{e}$ & -69.0 & Dellien et al. (1976) \\
(7) $\mathrm{Cr}(\mathrm{OH})_{2}^{+}+2 \mathrm{H}_{2} \mathrm{O} \rightleftharpoons \mathrm{CrO}_{4}^{2-}+6 \mathrm{H}^{+}+3 \mathrm{e}$ & -62.8 & comb. (1), (2), (6) \\
(8) $\mathrm{Cr}(\mathrm{OH})_{3}+\mathrm{H}_{2} \mathrm{O} \rightleftharpoons \mathrm{CrO}_{4}^{2-}+6 \mathrm{H}^{+}+3 \mathrm{e}$ & -54.2 & comb. (1), (3), (6) \\
(9) $\mathrm{Cr}(\mathrm{OH})_{4}^{-} \rightleftharpoons \mathrm{CrO}_{4}^{2-}+4 \mathrm{H}^{+}+3 \mathrm{e}$ & -45.2 & comb. (1), (4), (6)
\end{tabular}




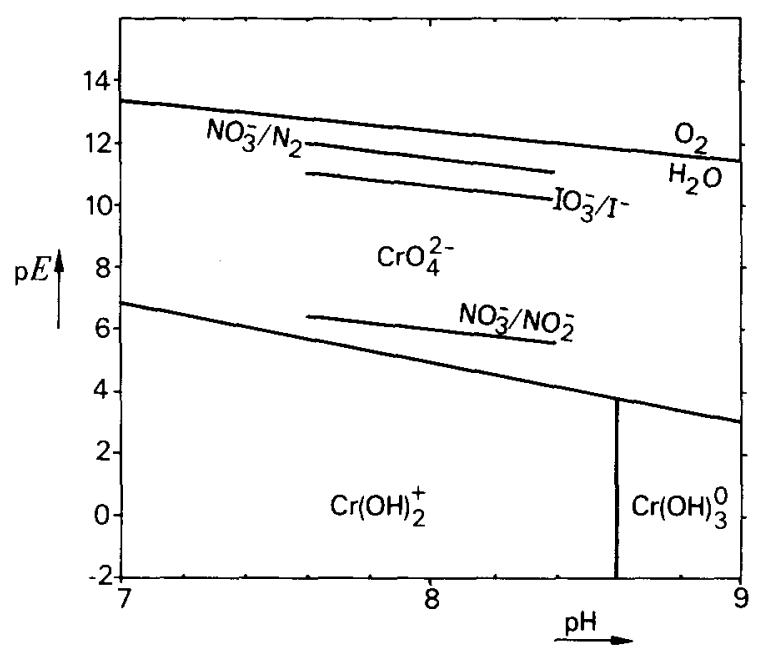

Fig. 2. pe-pH stability diagram for dominant chromium species in seawater, showing equimolar boundaries. Also indicated are equi-activity boundaries for some species in the nitrogen and iodine systems.

seawater, based on iodide-iodate and nitrate-nitrogen couples, as suggested by Liss et al. (1973). Although the metastable nitrate-nitrite redox couple comes much closer in this respect, this does not imply that the $\mathrm{Cr}$ (VI)/ $\mathrm{Cr}$ (III) ratio is controlled by the complicated microbiologically induced nitrogen cycle in seawater. Recently Nakayama et al. (1981a) reported the presence of dissolved organic $\mathrm{Cr}$ (III)-species in the Pacific Ocean and in the Japan Sea. These species constituted about half of the dissolved chromium in their samples. In another publication Nakayama et al. (1981b) suggest that such species are inert to oxidation. If their observations are correct some relevant species have indeed been overlooked in the past.

\section{RATE OF OXIDATION}

Elderfield (1970) supposed that the kinetics of oxidation for $\mathrm{Cr}$ (III) to $\mathrm{Cr}$ (VI) are slow, which would explain the apparent absence of thermodynamic equilibrium. Emerson et al. (1979) and Cranston and Murray (1978) showed that the $\mathrm{Cr}$ (III)/Cr(VI) ratio responds to changes in the redox conditions. Schroeder and Lee (1975) carried out experiments on the oxidation of $\mathrm{Cr}$ (III) in model freshwaters. They were able to demonstrate oxidation of $\mathrm{Cr}$ (III) by oxygen at a slow rate, the activation energy being $92 \mathrm{~kJ} \mathrm{~mol}^{-1}$. No significant differences were found for variation of $\mathrm{pH}$, although protons play a role in the oxidation reaction. The same authors also tested the effect of the presence of naturally occurring mineral phases. They found that $\mathrm{Cr}$ (III) was strongly adsorbed onto sand, bentonite, and ferric oxyhydroxide. Only manganese dioxide had a strong effect on the oxidation; in a few days all $\mathrm{Cr}$ (III) was oxidized. 
Similar experiments were carried out in our laboratory. In addition to artificial seawater and natural seawater from the North Sea, artificial freshwater samples in the $\mathrm{pH}$ range 5.5-8 were used. The oxidation of $\mathrm{Cr}$ (III), using an initial concentration of $100 \mu \mathrm{g} \mathrm{l}^{-1}$, was repeatedly tested. Even after 6 weeks no $\mathrm{Cr}$ (VI) had been formed at room temperature, nor did raising the temperature to 310 and $320 \mathrm{~K}$ result in detectable oxidation of $\mathrm{Cr}$ (III). Adsorption of $\mathrm{Cr}$ (III) was measured using ${ }^{51} \mathrm{Cr}$ as a spike. The adsorption behaviour of $\mathrm{Cr}$ (III) during these experiments is illustrated by the curves given in Fig. 3. The results compare well with those of Nakayama et al. (1981b).

It would be speculative to apply such experimental results directly to chromium chemistry in the oceans. However, the results can be used in an order of magnitude estimation. Assuming that during the six weeks period $2 \mu \mathrm{g} \mathrm{Cr}$ (III) $\mathrm{l}^{-1}$ was oxidized (just below the limit of detection of $\mathrm{Cr}$ (VI) for the applied analytical method), that the average $\mathrm{Cr}$ (III) concentration during this period was $50 \mu \mathrm{gl}^{-1}$, and that first-order oxidation kinetics can be applied according to

$$
-\frac{\mathrm{d}[\mathrm{Cr}(\mathrm{III})]}{\mathrm{d} t} \simeq k[\mathrm{Cr}(\mathrm{III})]
$$

where $k=$ rate constant comprising the concentration of free oxygen, then

$k \simeq \frac{2}{50} \times \frac{365}{42} \simeq 0.35 \mathrm{y}^{-1}$

Assuming again that the $\mathrm{Cr}$ (III) concentration in the oceans is about $1.10^{-9} \mathrm{moll} \mathrm{l}^{-1}$, and the oxygen fugacity in the water column approximately equals that of the experiments, and temperature differences are neglected, then the production of $\mathrm{Cr}$ (VI) would be roughly

$\frac{\mathrm{d}[\mathrm{Cr}(\mathrm{VI})]}{\mathrm{d} t} \simeq 0.35 .10^{-9} \mathrm{moll}^{-1} \mathrm{y}^{-1}$

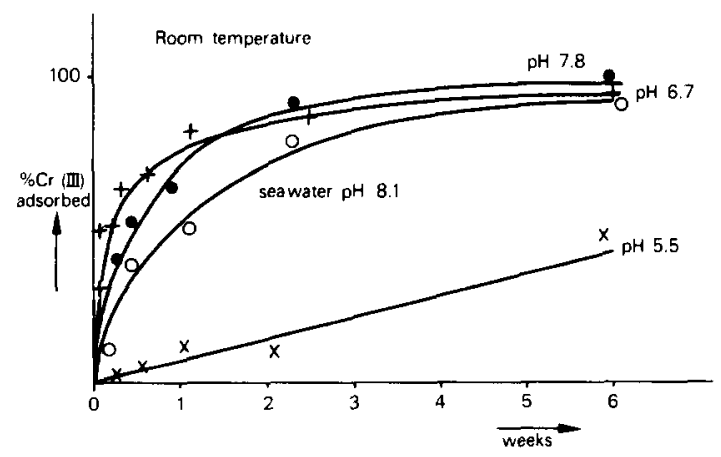

Fig. 3. Typical curves obtained by monitoring adsorption of $\mathrm{Cr}$ (III) onto glass container walls, showing effect of $\mathrm{pH}$ and ionic medium. 
The fluxes of chromium in the exogenic cycle are shown in a simple diagram in Fig. 4; some relevant values are given in Table II. Steady state requires that $F_{1}=F_{4}$ and $F_{2}=F_{3}$.

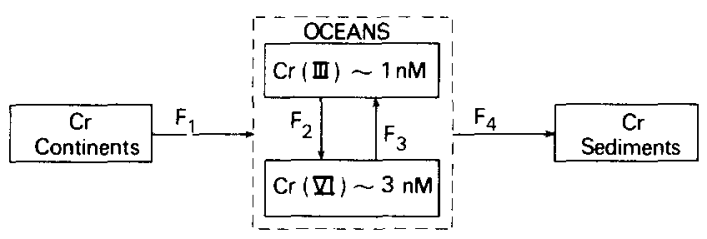

Fig. 4. Fluxes of chromium in the exogenic cycle. (Estimated concentrations of chromium species in the oceans after Nakayama et al. (1981a).)

TABLE II

Some relevant data on the hydrogeochemical cycle of chromium

$\begin{array}{ll}\text { Annual discharge of world rivers } & 0.376 \times 10^{17} \mathrm{ly}^{-1} \\ \text { Total ocean volume } & 1.3 \times 10^{21} \mathrm{l}^{-1} \\ \text { Cr concentration in river water } & \sim 1 \times 10^{-6} \mathrm{gl}^{-1} \\ \text { Cr concentration in ocean water } & \sim 0.2 \times 10^{-6} \mathrm{gl}^{-1} \\ \text { Ocean residence time of } \mathrm{Cr} & \sim 7000 \mathrm{y}\end{array}$

From the foregoing it would follow that $F_{3} \simeq 600 F_{1}$. This means that the fluctuations in the chromium speciation would be much greater than they actually are. Therefore either the rate constant or the $\mathrm{Cr}$ (III) concentration in the oceans must be much lower.

The presence of $\mathrm{MnO}_{2}$ has, indeed, a remarkable effect on the oxidation of $\mathrm{Cr}$ (III). Both reagent-grade and natural $\mathrm{MnO}_{2}$ were used in our experiments. Typical curves, representing sorption and oxidation, are presented in Figs. 5 and 6. These curves demonstrate that the presence of $\mathrm{MnO}_{2}$ in both freshwater and seawater helps to oxidize $\mathrm{Cr}$ (III) in a sequence of adsorption, surface oxidation and desorption. Similar results were reported by Nakayama et al. (1981b). The kinetics of these processes are significantly slower in seawater than in freshwater, due to the competition between $\mathrm{Cr}$ (III) and other cations for reactive surface sites. Schroeder and Lee (1975) showed that lower concentrations of $\mathrm{MnO}_{2}$ in suspension result in lower oxidation rates. From the results presented in Figs. 5 and 6 a rate constant of oxidation can be calculated, using the relation

$-\frac{\mathrm{d}[\mathrm{Cr}(\mathrm{III})]}{\mathrm{d} t} \simeq k\left[\mathrm{MnO}_{2}\right][\mathrm{Cr}(\mathrm{III})]$

From the results of the experiments, the rate constant can be estimated as $k \simeq 2.10^{5} \mathrm{lmol}^{-1} \mathrm{y}^{-1}$.

In order to compare these results with the oxidation of $\mathrm{Cr}$ (III) in the ocean, it is important to know the concentration ratio of suspended $\mathrm{MnO}_{2}$ 


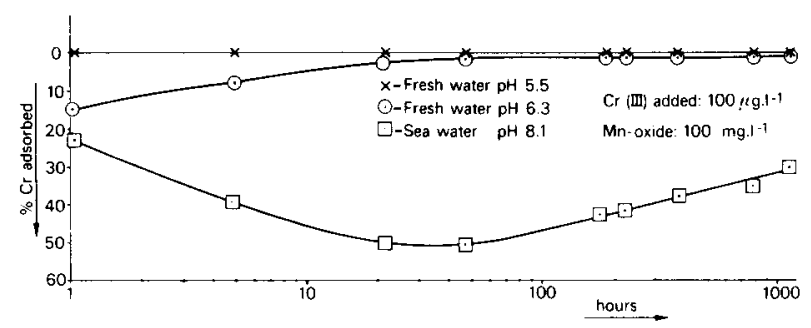

Fig. 5. Adsorption of $\mathrm{Cr}$ (III) by manganese oxide in freshwater and in seawater.

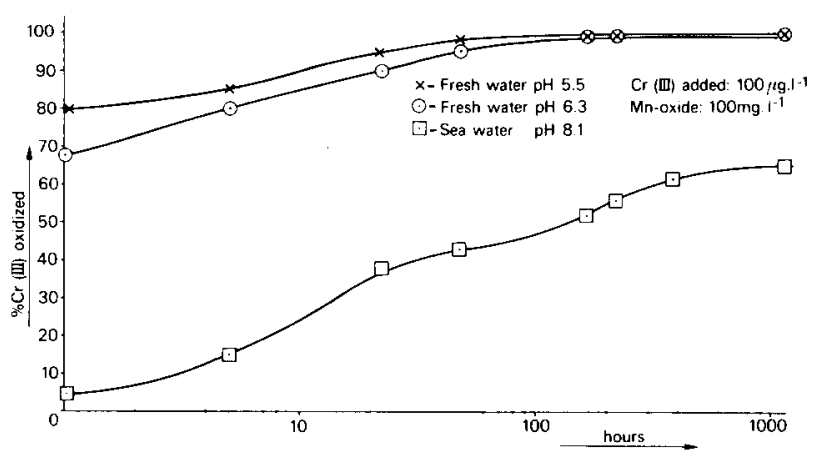

Fig 6. Oxidation of $\mathrm{Cr}$ (III) by manganese oxide in freshwater and in seawater.

and $\mathrm{Cr}$ (III). The sedimentation of manganese as $\mathrm{MnO}_{2}$, including ferromanganese oxide coatings on sediment particles, is $<10 \%$ of the manganese input in the oceans. An estimate of the $\mathrm{MnO}_{2}$ concentration in the water column can be based on the average sedimentation rates of marine sediments, their $\mathrm{MnO}_{2}$ content, and the settling velocities of particulate matter. Our 'order of magnitude' estimate is

$\left[\mathrm{MnO}_{2}\right] \simeq 10^{-10} \mathrm{moll}^{-1}$

Adopting a $\mathrm{Cr}$ (III) concentration of about $1.10^{-9} \mathrm{moll}^{-1}$, the rate of catalyzed oxidation would be

$\frac{\mathrm{d}[\mathrm{Cr}(\mathrm{VI})]}{\mathrm{d} t} \simeq 2.10^{-14} \mathrm{~mol} \mathrm{l}^{-1} \mathrm{y}^{-1}$

This amounts to $F_{3} \simeq 0.1 F_{1}$, which in our opinion is not far beyond realistic expectations.

Similar rates could have been calculated for the $\mathrm{Cr}(\mathrm{III})-\mathrm{O}_{2}$-seawater system using rate constants far below the detection limits in the experiments. Based on the experiments, it is not clear whether oxidation by dissolved oxygen or by suspended $\mathrm{MnO}_{2}$ is responsible for maintaining the oceanic chromium speciation.

Nakayama et al. $(1981 \mathrm{a}, \mathrm{b})$ suggested, that ocean sediments play a major role in the oxidation of $\mathrm{Cr}$ (III), a theory which cannot easily be tested be- 
cause one should be able to estimate the 'equilibrium concentration' of sedimentary $\mathrm{MnO}_{2}$ per liter of near-bottom water and the residence time of that water in the near-bottom layer. In any case, sediments covered by manganese nodules are likely to play a role in the conversion of trivalent to hexavalent chromium. Chuecas and Riley (1966) reported a low efficiency of hydrous manganese oxide in co-precipitation of chromium from solution. In a series of experiments on adsorption of transition metals onto manganese oxide, we found that the solution turned yellow, demonstrating the oxidation of $\mathrm{Cr}$ (III) into $\mathrm{Cr}$ (VI). Glasby (1974) concluded that chromium in manganese nodules is almost exclusively present in the detrital phase. He mentioned that the low tendency of nodule material to absorb anions such as $\mathrm{CrO}_{4}^{2-}$ could explain this behaviour.

\section{SINKS FOR CHROMIUM}

In Table III the equilibrium concentrations of chromium with respect to the least soluble mineral phases are calculated. These data show that formation of distinct $\mathrm{Cr}$ (III) mineral phases is unlikely. It is known, however, that adsorption of $\mathrm{Cr}$ (III) onto iron hydroxides and other mineral phases in the marine environment is a very effective mechanism for its removal from seawater. Precipitation of distinct $\mathrm{Cr}$ (VI) mineral phases can also be ruled out. Co-precipitation with barium sulphate is possible, but according to Betechtin (1977), the chromate ion apparently has little affinity for a sulphate lattice. Therefore, the most likely sink for $\mathrm{Cr}(\mathrm{VI})$ is adsorption after prior reduction to $\mathrm{Cr}$ (III). This reduction could take place: (a) by biological activity in the water column; (b) by diffusion into the anoxic layers of sediments; (c) in anoxic basins.

There is as yet no evidence that the first two processes take place. Reduction in anoxic basins is demonstrated by Cranston and Murray (1978) and by Emerson et al. (1979). The latter assume that $\mathrm{Cr}$ (VI) is readily reduced below the oxic-anoxic boundary (although their results do not quite confirm this), but that $\mathrm{Cr}$ (III) is less rapidly oxidized above this boundary. They calculate a residence time of $6-20$ days for $\mathrm{Cr}$ (III) in the oxic layer. From

\section{TABLE III}

Solubility of least soluble $\mathrm{Cr}$ (III)- and $\mathrm{Cr}(\mathrm{VI})$-mineral phases in seawater (Dissociation data from Baes and Mesmer (1976) and from Charlot (1969))

\begin{tabular}{|c|c|c|c|c|}
\hline \multirow[b]{2}{*}{ Mineral Phase } & \multirow[b]{2}{*}{$\mathrm{p} K^{1}$ diss $(I=0.75)$} & \multirow[b]{2}{*}{ Calculated for } & \multicolumn{2}{|c|}{ Solubility $\left(\mathrm{mol} \mathrm{Cr} \mathrm{l}^{-1}\right)$} \\
\hline & & & pH 7.5 & pH 8.2 \\
\hline $\mathrm{Cr}(\mathrm{OH})_{3}$ & 28.6 & & $10^{-4.65}$ & $10^{-5.2}$ \\
\hline $\mathrm{CrPO}_{4}$ & 20.4 & $C_{P_{\text {(tot) }}}=2 \times 10^{-6}$ & $10^{-5.22}$ & $10^{-4.5}$ \\
\hline $\mathrm{BaCrO}_{4}$ & 8.76 & $\mathrm{C}_{\mathrm{Ba}}=1.5 \times 10^{-7}$ & $10^{-1.9}$ & $10^{-1.9}$ \\
\hline
\end{tabular}


their description of the chemistry along the vertical profile, i.e. their reference to a layer of manganese oxide just above the oxic-anoxic boundary, it can be expected that in such systems $\mathrm{MnO}_{2}$, locally produced in relatively high concentrations, helps to diminish the residence time of $\mathrm{Cr}$ (III) as compared to a system with dissolved oxygen as the only oxidant.

\section{CONCLUSIONS}

Oxidation of $\mathrm{Cr}$ (III) in seawater by oxygen is a very slow process. Adsorption on manganese oxide, followed by oxidation at the surface, helps considerably to convert $\mathrm{Cr}$ (III) into the thermodynamically stable $\mathrm{Cr}$ (VI). Because of the low concentration of suspended $\mathrm{MnO}_{2}$ in the oceans, it is not clear whether this catalyzed oxidation is quantitatively more important than the direct oxidation by dissolved oxygen; the contribution of $\mathrm{MnO}_{2}$ in marine sediments is hard to assess. Sinks for $\mathrm{Cr}$ (III) are adsorption onto ferric oxyhydroxide clays, etc.; sinks for $\mathrm{Cr}(\mathrm{VI})$ are probably identical, following the reduction of $\mathrm{Cr}$ (VI). The marine part of the geochemical cycle of chromium is still not fully documented.

\section{REFERENCES}

Baes, C.F. and Mesmer, R.E., 1976. The hydrolysis of cations. Wiley, New York, 489 pp.

Betechtin, A.G., 1977. Lehrbuch des speziellen Mineralogie (7. Auflage). VEB Deutscher Verlag für Grundstoffenindustrie, Leipzig, $683 \mathrm{pp}$.

Charlot, G., 1969. Les réactions chimiques en solution. Masson et Cie, Paris, 463 pp.

Chuecas, L. and Riley, J.P., 1966. The spectrophotometric determination of chromium in seawater. Anal. Chim. Acta, 35: 240-246.

Cranston, R.E. and Murray, J.W., 1978. The determination of chromium species in natural waters. Anal. Chim. Acta, 99: 275-282.

Dellien, I., Hall, F.M. and Hepler, L.G., 1976. Chromium, molybdenum, and tungsten: thermodynamic properties, chemical equilibria, and standard potentials. Chem. Rev. $76: 283-310$.

EIderfield, H., 1970. Chromium speciation in seawater. Earth Planet. Sci. Lett., 9: 10-16.

Emerson, S., Cranston, R.E. and Liss, P.S., 1979. Redox species in a reducing fjord: equilibrium and kinetic considerations. Deep-Sea Res., 26A: 859-878.

Glasby, G.P., 1974. Mechanisms of incorporation of manganese and associated trace elements in marine manganese nodules. Oceanogr. Mar. Biol. Ann. Rev., 12: 11-40.

James, R.O. and Healy, T.W., 1972. Adsorption of hydrolyzable metal ions at the oxide/ water interface. III. A thermodynamic model of adsorption. J. Colloid Interface Sci., 40: $65-81$.

Liss, P.S., Herring, J.R. and Goldberg, E.D., 1973. The iodide/iodate system in seawater as a possible measure of redox potential. Nature, 242: 108-109.

Nakayama, E., Tokoro, H., Kuwamoto, T. and Fujinaga, T., 1981a. Dissolved state of chromium in seawater. Nature, 290: 768-770.

Nakayama, E., Kuwamoto, T., Tsurubo, S. and Fujinaga, T., 1981b. Chemical speciation of chromium in seawater. Part 2. Effects of manganese oxides and reducible organic materials on the redox processes of chromium. Anal. Chim. Acta, 130: 401-404.

Schroeder, D.C. and Lee, G.F., 1975. Potential transformations of chromium in natural waters. Water, Air, Soil Pollut., 4: 355-365. 